\title{
The Flow Rate Influence on the Interaction of a Radial Pump Impeller and the Diffuser
}

\author{
A. Akhras, M. El Hajem, J.-Y. Champagne, and R. Morel \\ Laboratoire de Mécanique des Fluides et d'Acoustique, Composante INSA Lyon, Villeurbanne, France
}

This article presents the results of a detailed flow investigation within a centrifugal pump equipped with a vaned diffuser. The measurements were made with a laser Doppler velocimeter and were carried out at different operating points. The flow was investigated for different rotor-stator relative positions.

Unsteady velocity measurements, obtained in phase with the rotor angular position, gave access to the flow inside the impeller channels where three sections were explored. In the diffuser, five sections were studied. Thus, time resolved details of the flow were examined for a better understanding of the complex unsteady flow existing between the two interacting blade rows.

Results obtained at different operating conditions show that the rotor-stator interaction is affected by the diffuser position and the flow rate.

Keywords Centrifugal Pump, Internal Flow, LOA Investigation, Rotor Stator Interaction

For a centrifugal pump equipped with a vaned diffuser, the steadiness of the flow at the rotor-stator interface requires a large distance between both components. Otherwise, the unsteady flow that enters the diffuser represents a source of low efficiency. Furthermore, the internal flow of the impeller can be affected by asymmetric downstream conditions, which results in additional flow unsteadiness and instabilities.

A number of authors have treated the problem of the interaction of the impeller and its surroundings. Miner et al. (1989) used a laser velocimeter to measure velocities within the impeller

Received 25 June 2002; accepted 1 July 2002.

Address correspondence to A. Akhras, Laboratoire de Mécanique des Fluides et d'Acoustique UMR-CNRS 5509, Composante INSA de Lyon, Bât, J. Jacquard 27, Avenue Albert Einstein, Villeurbanne 69621, France.E-mail: akhras@insa-lyon.fr

and the volute of a centrifugal pump and found the relative velocity components distribution varies with the circumferential angle relative to the volute cutwater. Liu et al. (1994) has also used LDA for the internal flow investigation and determined that the asymmetric volute alters the relative flow. They found that the flow rate from each impeller passage varied with the volute circumferential position by up to 25 percent at an offdesign flow rate. Inoue and Cumpsty (1984), Sideris and van den Braembussche (1987) and Arndt et al. (1989, 1990) have been concerned with the action of the diffuser.

For internal rotor flow, preview studies have revealed the presence of a jet-wake structure at the discharge of radial impeller. These studies were mainly concerned with compressors or machines run with air as done by Eckardt (1975, 1976), Johnston (1976), Johnson (1978), Rohne and Banzhaf (1991) Ubaldi et al. (1993), and more recently, Wuibaut et al. (2001). However, Krain (1988) found a velocity profile that differed widely from the jetwake type flow.

For rotor-stator interaction Cattanei et al. (1998) studied and discovered a positive and negative incidence variation occurring on the diffuser vane as a consequence of the alternating passage of blade wakes and free-stream flow.

During this study, LDA measurements revealed the presence of a jet-wake flow structure. The location and the extension of the wake seem to be affected by the proximity of the diffuser vanes and the flow rate.

\section{EXPERIMENTAL SETUP}

\section{The SHF Impeller}

The test impeller, made for "Société Hydrotechnique de France" and shown in Figure 1, is a low-specific speed $\left(\omega_{\mathrm{s}}=\right.$ 0.577 ) shrouded impeller. It has 7 backswept blades with an exit angle of $22.5^{\circ}$ relative to the tangential direction. The main geometric data of the impeller and its operating conditions are listed in Table 1. The impeller was run with a vaned diffuser and an industrial-type spiral casing. The diffuser is a straight wall constant width type with six vanes (Figure 1); its main dimensions are listed in Table 1. 


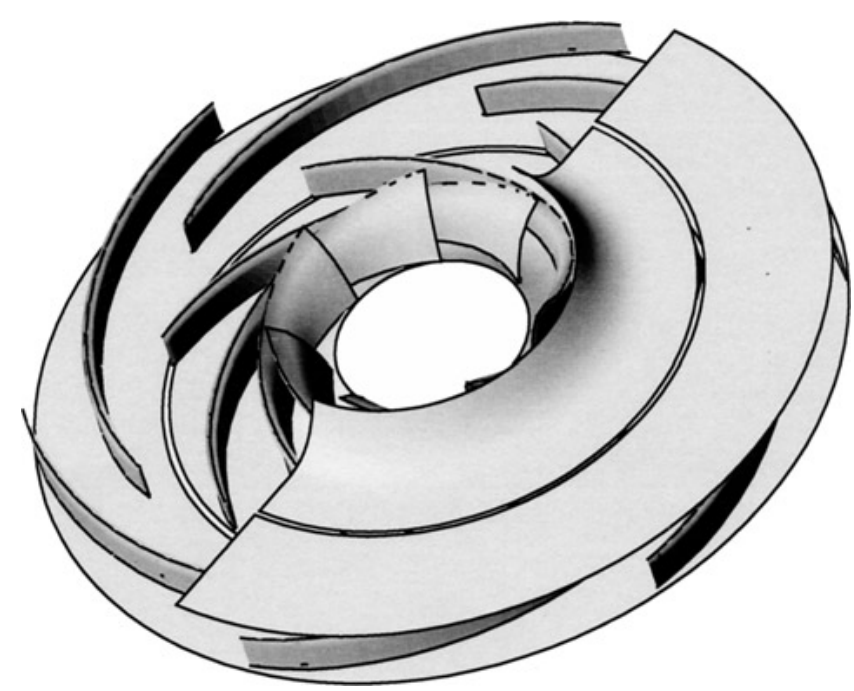

FIGURE 1

Test impeller and vaned diffuser.

\section{Test Facility and Measuring Equipment}

The experiments were performed on a closed rig equipped for the overall performance characterization of the machine. Water enters the impeller through a straight suction pipe, $1.4 \mathrm{~m}$ in length. The net flow rate traversing the pump is measured by an electromagnetic flow meter. The impeller is driven by a variable speed DC motor of $45 \mathrm{~kW}$ power at $1500 \mathrm{rpm}$ mounted in balance mode for torque measurement. The velocity distribution at the impeller discharge and in the diffuser was obtained by using an LDA system detailed by Akhras et al. (2000).

TABLE 1

Impeller and diffuser characteristics

\begin{tabular}{ll}
\hline & \multicolumn{1}{c}{ Description } \\
\hline Impeller parameter & \\
$\mathrm{R}_{1}=98.25 \mathrm{~mm}$ & Inlet blade radius at the shroud \\
$\mathrm{R}_{2}=177.25 \mathrm{~mm}$ & Impeller exit radius \\
$\mathrm{b}_{2}=26.7 \mathrm{~mm}$ & Blade height at exit \\
$\mathrm{Z}=7$ & Blade number \\
$\beta_{2 \mathrm{~g}}=22.5^{\circ}$ & Blade angle \\
$\mathrm{Q}_{\mathrm{n}}=0.0774 \mathrm{~m}^{3} / \mathrm{s}$ & Design flow rate \\
$\mathrm{N}=1188 \mathrm{rpm}$ & Rotational speed \\
$\phi=0.118$ & Design flow coefficient \\
$\psi=0.481$ & Design head coefficient \\
$\omega_{\mathrm{s}}=0.577$ & Specific speed \\
Diffuser parameter & \\
$\mathrm{R}_{3}=182 \mathrm{~mm}$ & Diffuser inlet radius \\
$\mathrm{R}_{4}=199.3 \mathrm{~mm}$ & Leading edge radius \\
$\mathrm{R}_{5}=258 \mathrm{~mm}$ & Diffuser exit radius \\
$\mathrm{b}_{3}=28.1 \mathrm{~mm}$ & Diffuser width \\
$\mathrm{Z}=6$ & Vane number \\
$\alpha_{3}=12^{\circ}$ & Vane angle \\
\hline
\end{tabular}

TABLE 2

Measuring Sections

\begin{tabular}{|c|c|c|c|}
\hline \multicolumn{2}{|c|}{$\begin{array}{l}\text { Angular position from } \\
\text { the diffuser leading edge }\left(^{\circ}\right)\end{array}$} & \multicolumn{2}{|c|}{$\begin{array}{l}\text { Radial position } \\
\mathrm{r}^{*}=\mathrm{r} / \mathrm{R}_{2}\end{array}$} \\
\hline I & $0^{\circ}$ & Impeller & 0.818 \\
\hline II & $3^{\circ}$ & & 0.909 \\
\hline III & $10^{\circ}$ & & 0.978 \\
\hline IV & $17^{\circ}$ & Diffuser & 1.017 \\
\hline V & $24^{\circ}$ & & 1.045 \\
\hline VI & $30^{\circ}$ & & 1.084 \\
\hline VII & $36^{\circ}$ & & 1.129 \\
\hline VIII & $43^{\circ}$ & & 1.191 \\
\hline IX & $50^{\circ}$ & & 1.636 \\
\hline$X$ & $57^{\circ}$ & & 1.214 \\
\hline
\end{tabular}

To relate the velocity measurement to the angular position of the impeller, an optical encoder is used to synchronize the measurements with the machine. The encoder fixed on the pump shaft gives the position of the measuring point in the blade-toblade plane with a resolution of 3600 angular readings for one shaft revolution.

\section{EXPERIMENTAL RESULTS}

In order to study the interaction of the impeller and diffuser, the flow was investigated for ten angular positions in the diffuser as given in Table 2 and shown in Figure 2. For each relative position, the flow was investigated at a minimum of eight radial sections in the impeller and diffuser (Table 2). For each radius, 16 points were explored in the axial direction. The measurements were made at the design flow $\mathrm{Q}^{*}=\mathrm{Q} / \mathrm{Q}_{n}=1$, and four offdesign flow rates: $\mathrm{Q}^{*}=0.8,0.7,0.6$, and 0.5 .

Only the velocity components in the radial and circumferential directions were measured; the velocity in the axial direction was not measured and was considered to be negligible. The velocity is presented for each position relative to the diffuser leading edge (Table 2) as a function of the angular position

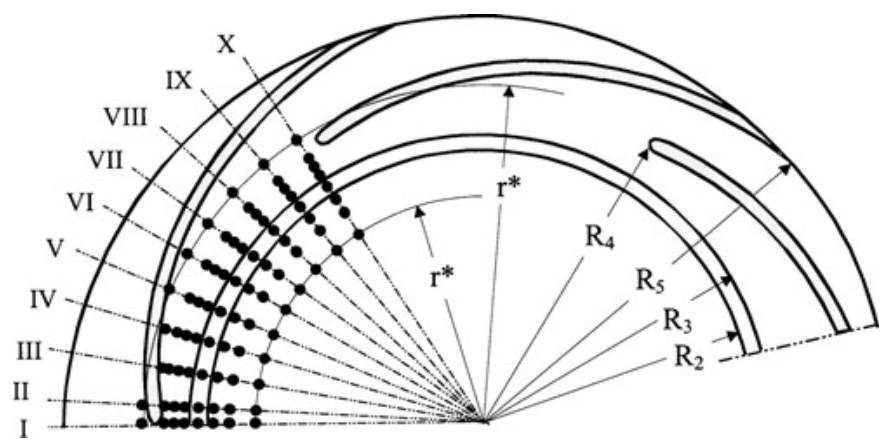

FIGURE 2

Details of the measuring sections. 


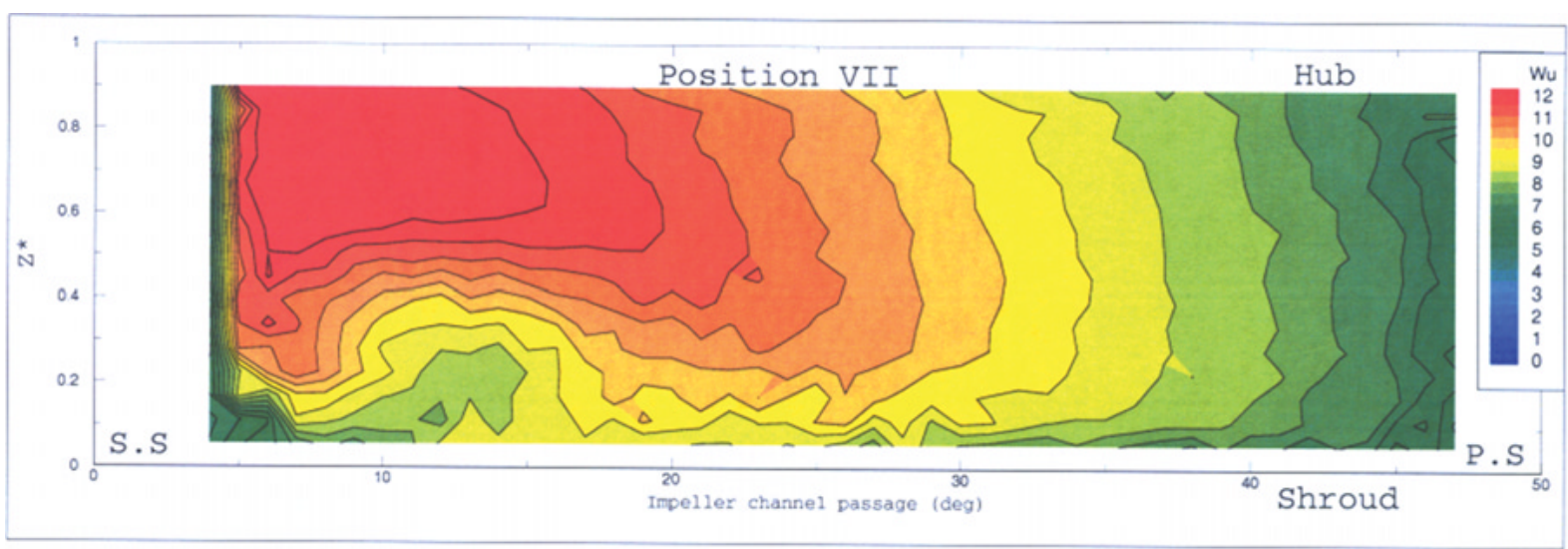

FIGURE 3

Relative circumferential component, $\mathrm{Q}^{*}=1, \mathrm{r}^{*}=0.818$, position VII.

within the impeller passages, and the axial distance $Z^{*}=Z / b_{2}$. The shroud and the hub are located at $Z^{*}=0$ and $Z^{*}=1$, respectively.

\section{Measurements at the Design Flow Rate $\left(Q^{*}=1\right)$}

At this flow rate we only present results obtained at $\mathrm{r}^{*}=$ 0.818 . At the other radii $\left(\mathrm{r}^{*}=0.909,0.978\right)$, the authors have found that the relative flow in the rotor was only slightly affected as the impeller passage approaches the diffuser leading edge Akhras et al. (2001).

The actual measurements obtained at the inner radius $\mathrm{r}^{*}=$ 0.818 are presented in Figures 3 and 4. In these figures the tangential component of the relative velocity $(\mathrm{Wu})$ is given as contours of constant relative velocity across the passage.

In Figure 3, the flow field was obtained at position VII located at the middle of the diffuser pitch. In this plane we can see that the flow is organized in a jet-wake structure characterized by a low relative velocity located in the shroud/suction side corner of the channel, the wake core is observed at $\mathrm{Z}^{*}=0.22$, and theta $=12^{\circ}$. The remaining of the passage is dominated by a more uniform flow constituting the jet and corresponding to a potential flow distribution with a constant velocity gradient in the blade to blade direction.

As the impeller passage proceeds towards the diffuser leading edge (Figure 4), the flow structure is globally unchanged, but a closer look at the wake position reveals that it is now more confined to the shroud. This is clearer in Figure 5 which shows the absolute velocity profile at the passage mid-height. Here we observe that the presence of the wake is only detected in the planes situated between II and VII. This flow reorganization seems to be induced by the presence of the diffuser vanes, especially at the proximity of the leading edge, and thus revealing the presence of secondary flows within the impeller.

At the diffuser entrance, a high incidence is observed as is shown by Figure 6 representing the absolute velocity field at $\mathrm{Z}^{*}=0.5$ and a relative rotor-stator position. The impeller rotates in the clockwise direction, and the period between the passage of two successive impeller blades in the front of the diffuser vane corresponds to 51 instants. The absolute flow angle corresponds

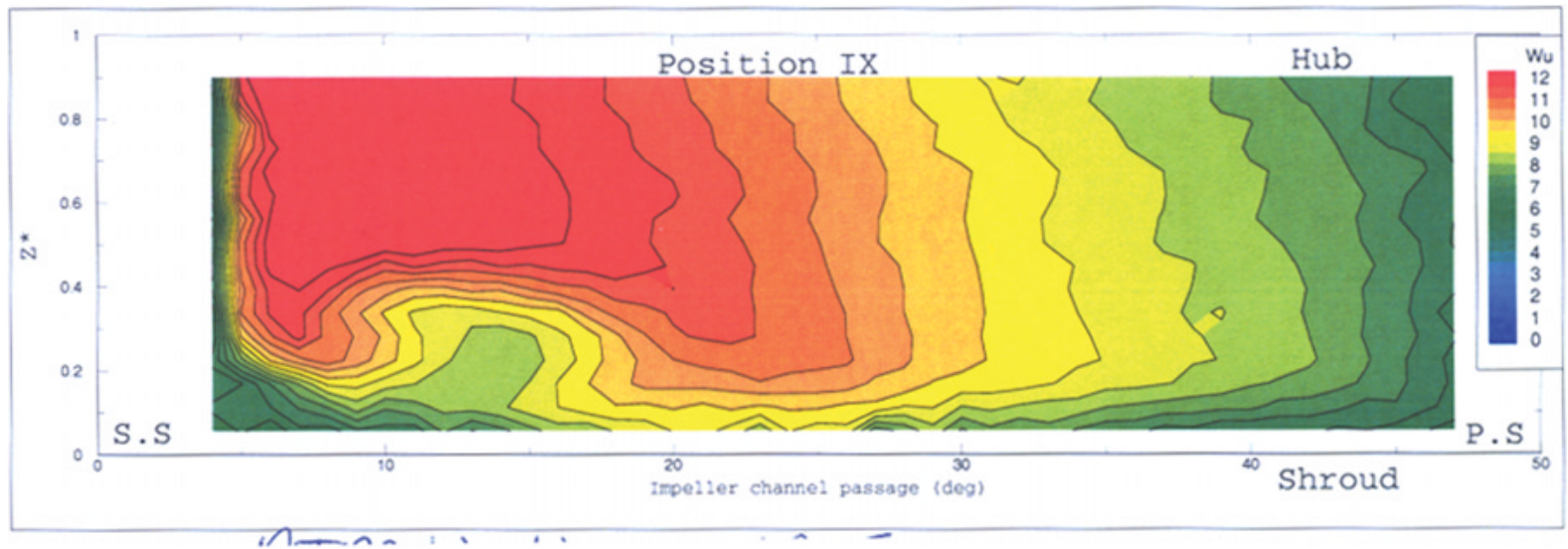

FIGURE 4

Relative circumferential component, $\mathrm{Q}^{*}=1, \mathrm{r}^{*}=0.818$, position IX. 


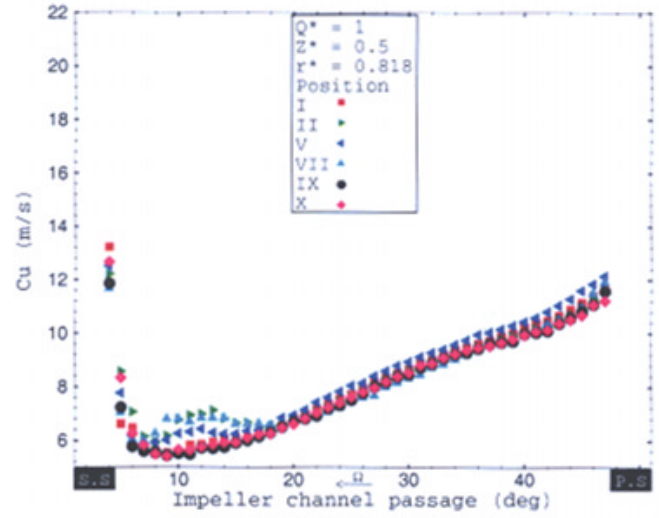

-a-

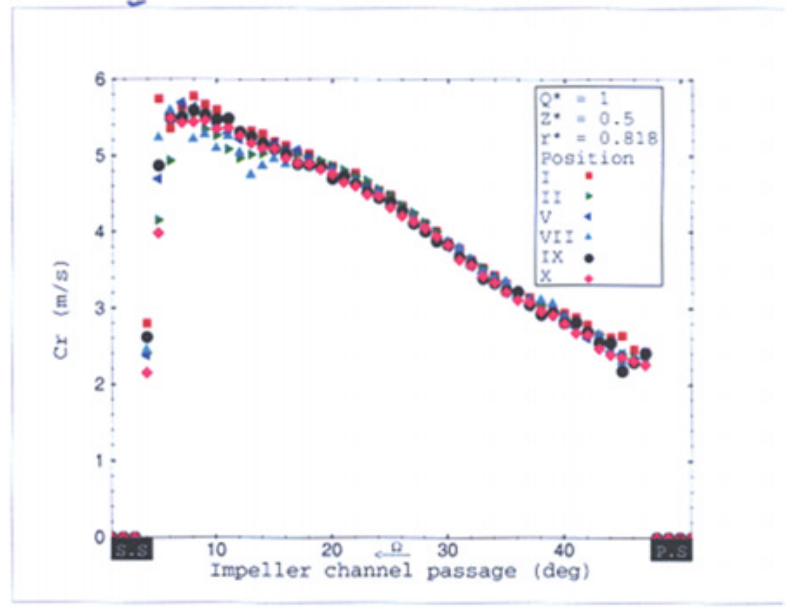

-b-

FIGURE 5

Flow field evolution, $\mathrm{Q}^{*}=1, \mathrm{Z}^{*}=0.5$, and $\mathrm{r}^{*}=0.818$. (a) Radial velocity $(\mathrm{Cu})$; (b) Tangential velocity $(\mathrm{Cr})$.

to an incidence of $-14^{\circ}$ at the diffuser leading edge, where a local flow blockage is registered.

\section{Measurements at Partial Flow Rate}

Figure 7 represents the results obtained at a partial flow rate $\mathrm{Q}^{*}=0.8$. The first conclusion is that the presence of the diffuser vanes seems to have a weaker influence on the impeller internal flow at the passage mid-height. In all measuring positions, the radial (Figure 7b) and tangential (Figure 7a) velocity profile indicate a flow distortion at the proximity of the suction side corresponding here also to the presence of the wake which is more developed at this operating point, whereas the remaining part of the passage is dominated by a potential flow constituting

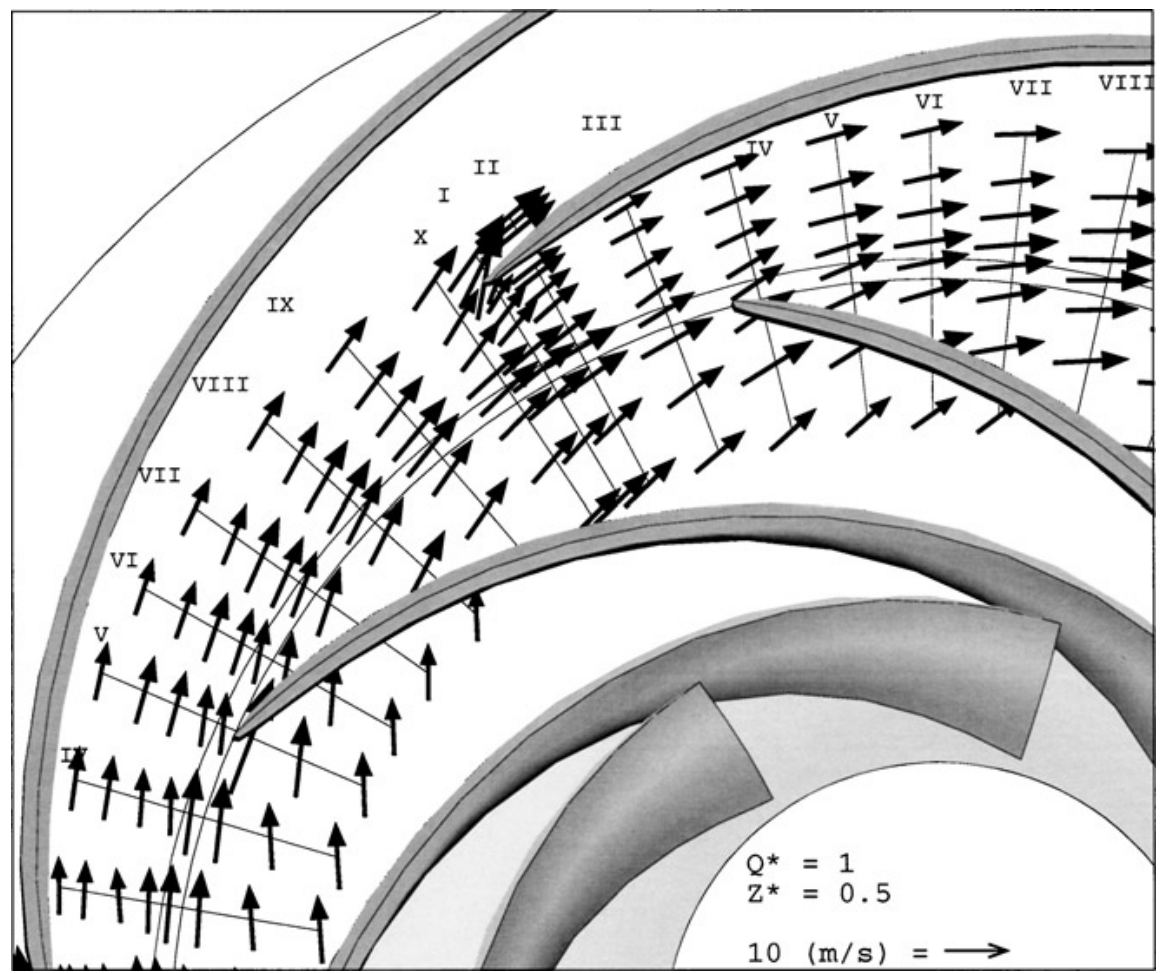

FIGURE 6

Absolute velocity field at $\mathrm{Q}^{*}=1, \mathrm{Z}^{*}=0.5$, and $\mathrm{T}=1 / 51$. 


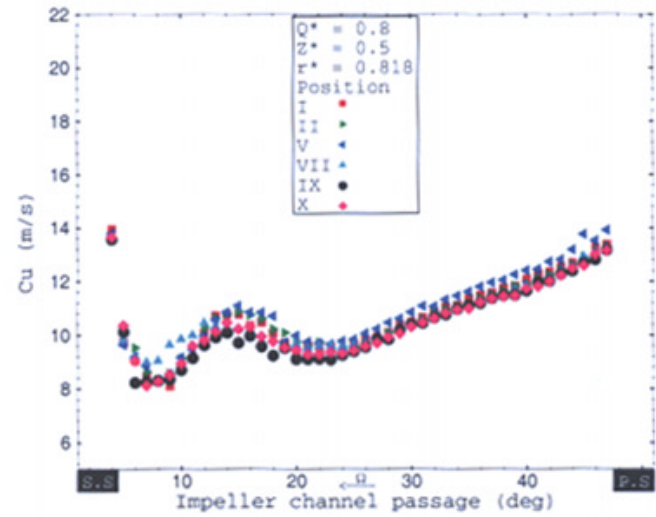

-a-

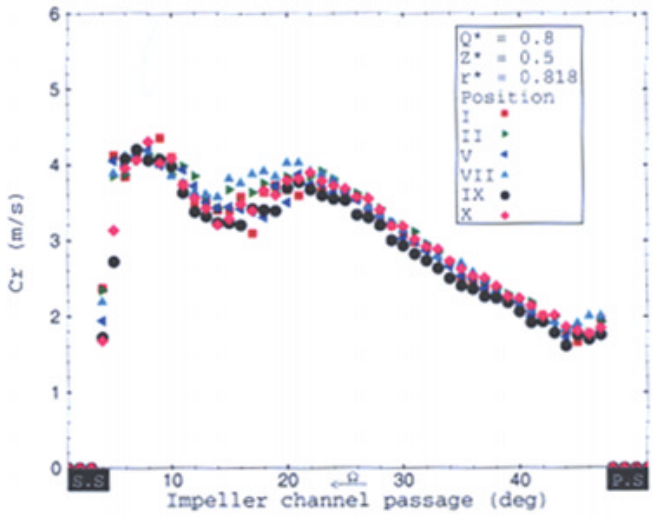

-b-

FIGURE 7

Flow field evolution, $\mathrm{Q}^{*}=0.8, \mathrm{Z}^{*}=0.5$, and $\mathrm{r}^{*}=0.818$. (a) Radial velocity $(\mathrm{Cu})$; (b) Tangential velocity $(\mathrm{Cr})$.

the jet where the velocity gradients correspond to those observed at the design flow rate.

The uniform flow distribution across the diffuser pitch and the better incidence at the diffuser leading edge (Figure 8) are in accordance with the fact that the rotor-stator matching point was found to be $\mathrm{Q}^{*}=0.8$ (El Hajem et al., 2001).
For $\mathrm{Q}^{*}=0.5$ and in the inner radius of the impeller $\left(\mathrm{r}^{*}=\right.$ 0.818 ), the velocity profile distribution is almost uniform at the passage mid-height $Z^{*}=0.5$. The circumferential velocity profile is identical in all measuring positions as shown in Figure 9a, whereas a relative dispersion is noticed in the radial component (Figure 10a).

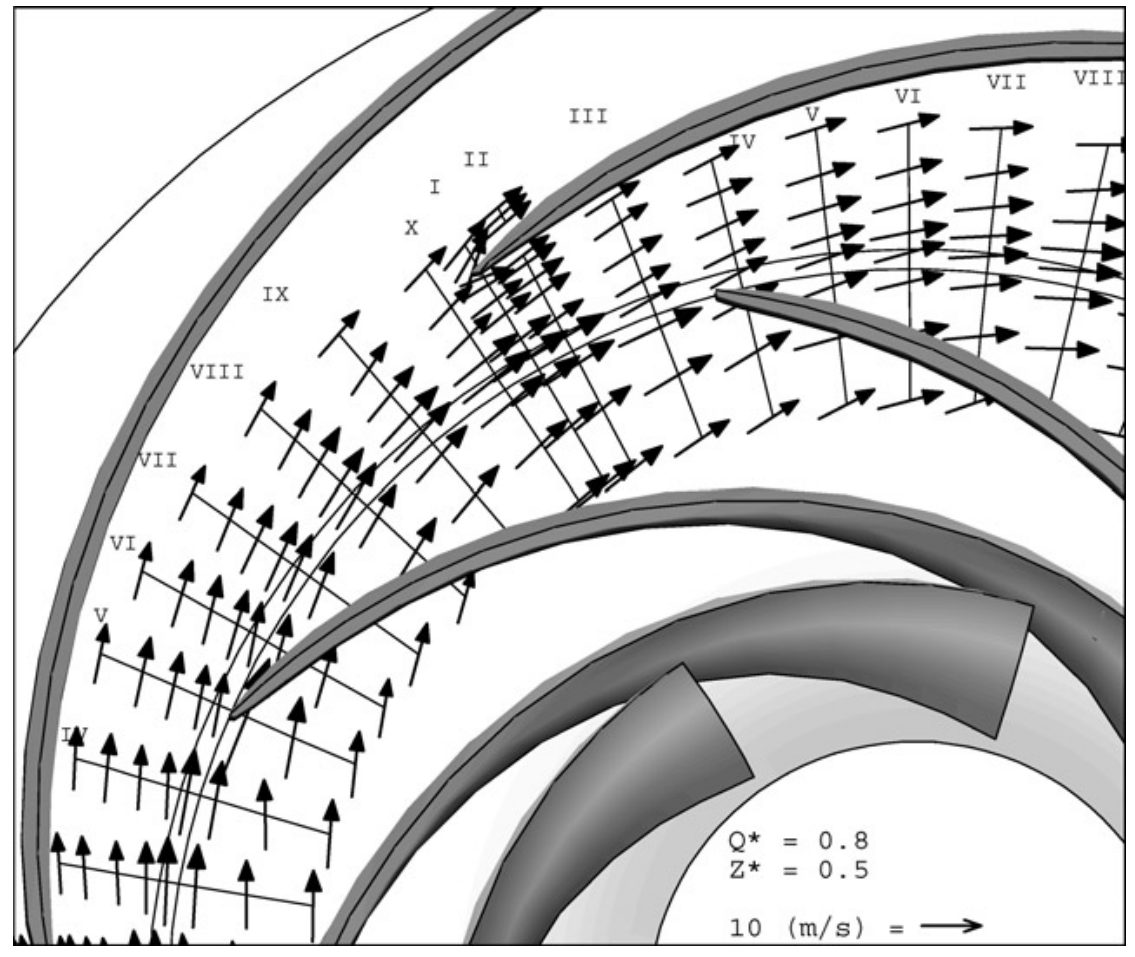

FIGURE 8

Absolute velocity field at $\mathrm{Q}^{*}=0.8, \mathrm{Z}^{*}=0.5$, and $\mathrm{T}=1 / 51$. 


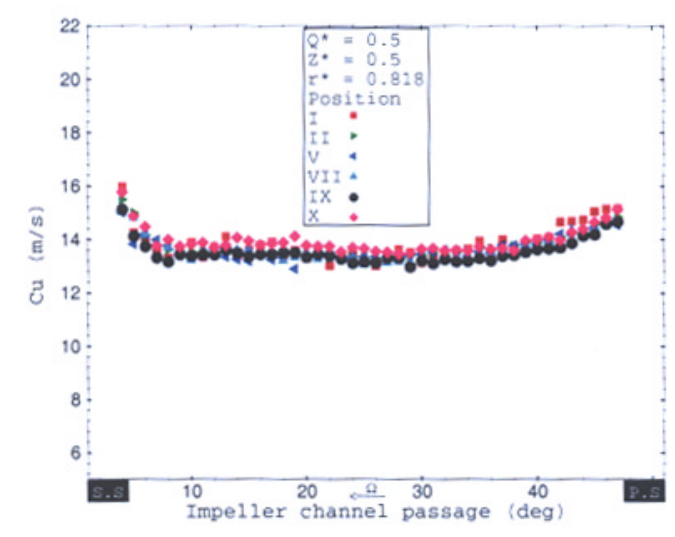

-a-

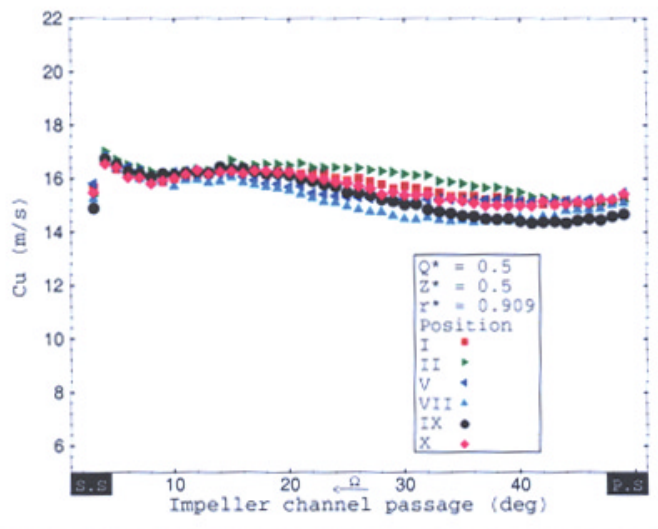

$-b-$

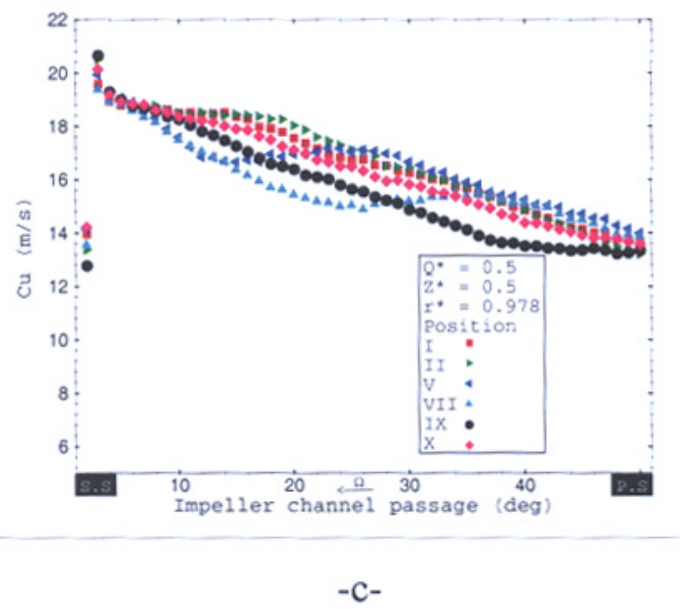

FIGURE 9

Tangential velocity evolution $\mathrm{Q}^{*}=0.5, \mathrm{Z}^{*}=0.5$. (a) $\mathrm{r}^{*}=$ 0.818 ; (b) $r^{*}=0.909$; (c) $r^{*}=0.978$.
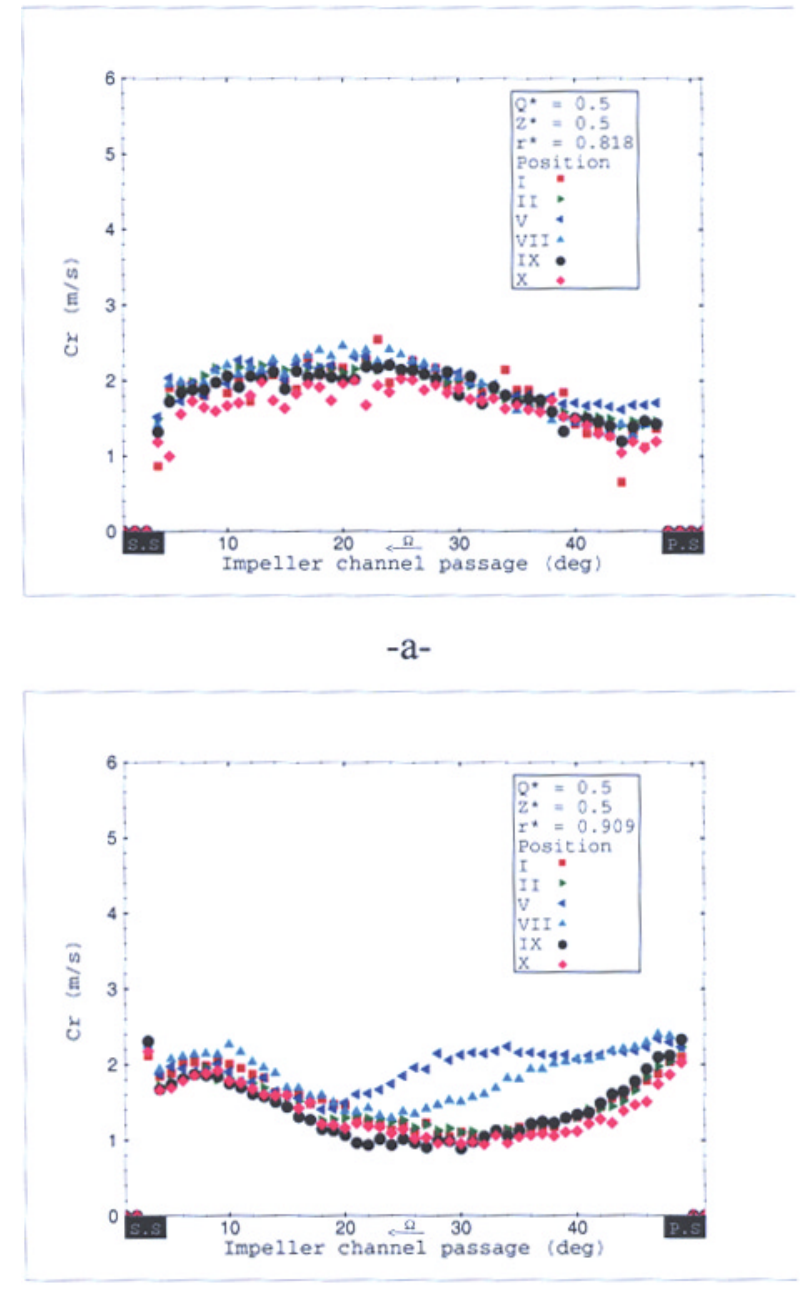

$-b-$

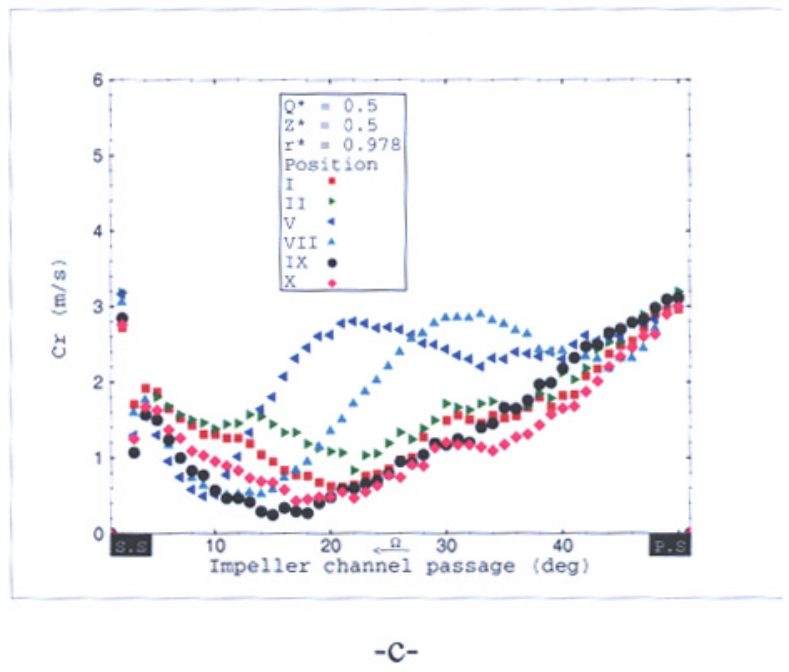

FIGURE 10

Radial velocity evolution $\mathrm{Q}^{*}=0.5 . \mathrm{Z}^{*}=0.5$. (a) $\mathrm{r}^{*}=0.818$; (b) $\mathrm{r}^{*}=0.909$; (c) $\mathrm{r}^{*}=0.978$. 

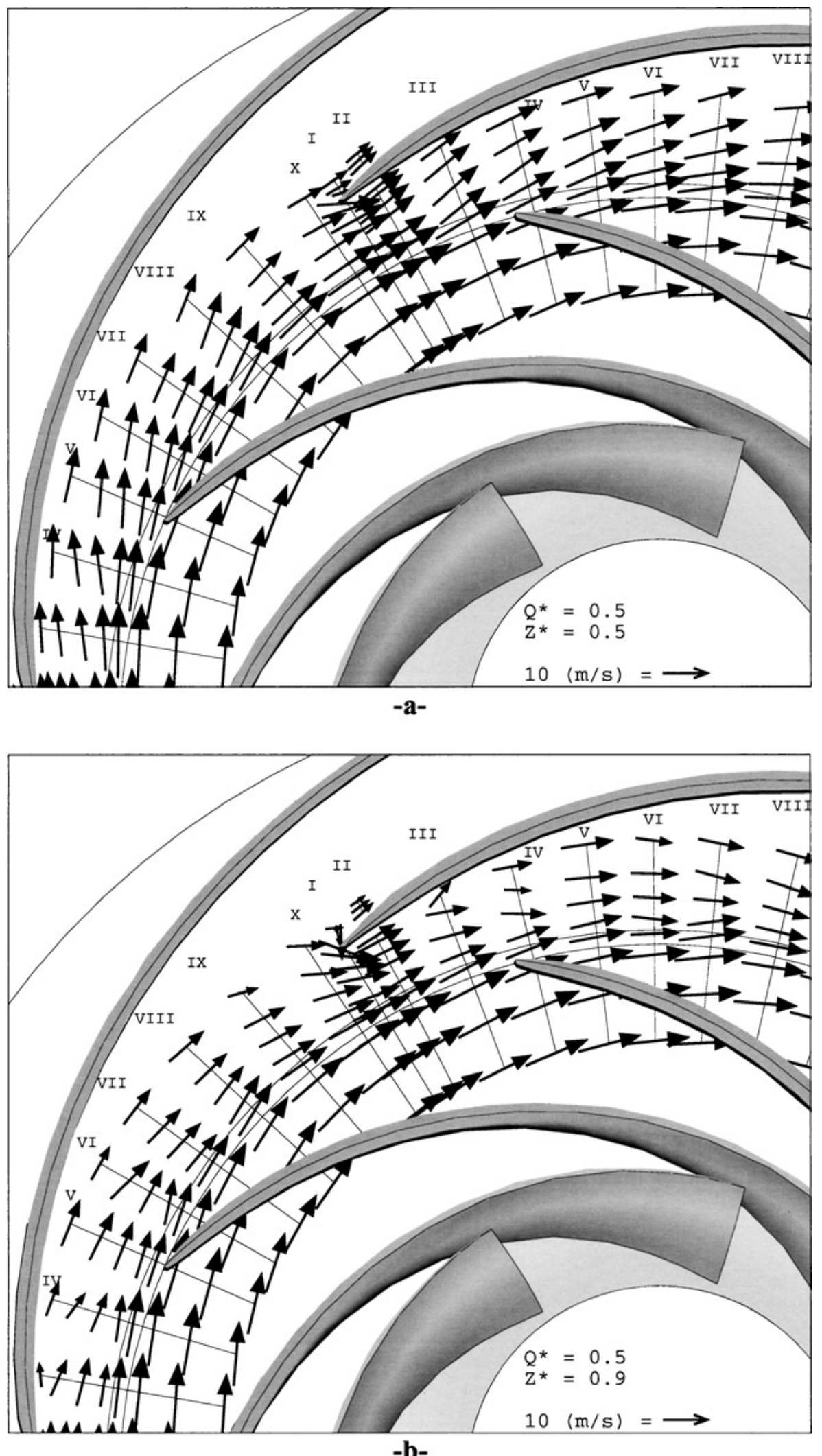

FIGURE 11

Absolute velocity field at $Q^{*}=1, T=1 / 51$. (a) $Z^{*}=0.5$; (b) $Z^{*}=0.9$. 
At the impeller exit, the velocity profile has a negative gradient in the spanwise direction at all measuring positions, except for positions $\mathrm{V}$ and VII, where we notice a uniform $\mathrm{Cu}$ at the passage center corresponding to a high radial velocity as measured at $\mathrm{r}^{*}=0.909$ (Figure 10b) and 0.978 (Figure 10c).

In the other positions, the radial component distribution presents a minimum which is displaced from the pressure side towards the suction side with the increasing radius. This flow field seems to correspond to a maximum local flow in the passage center when it faces the center of the diffuser pitch. At this time the suction side of the impeller passage approaches the diffuser leading edge, and the relative flow is slowed by the proximity of the diffuser vanes. Moreover, a positive incidence at the vanes leading edge is at the origin of a flow going around it and a negative $\mathrm{Cr}$ is registered as seen in Figures 11 and 12. This accentuates the flow blockage which is compensated by a

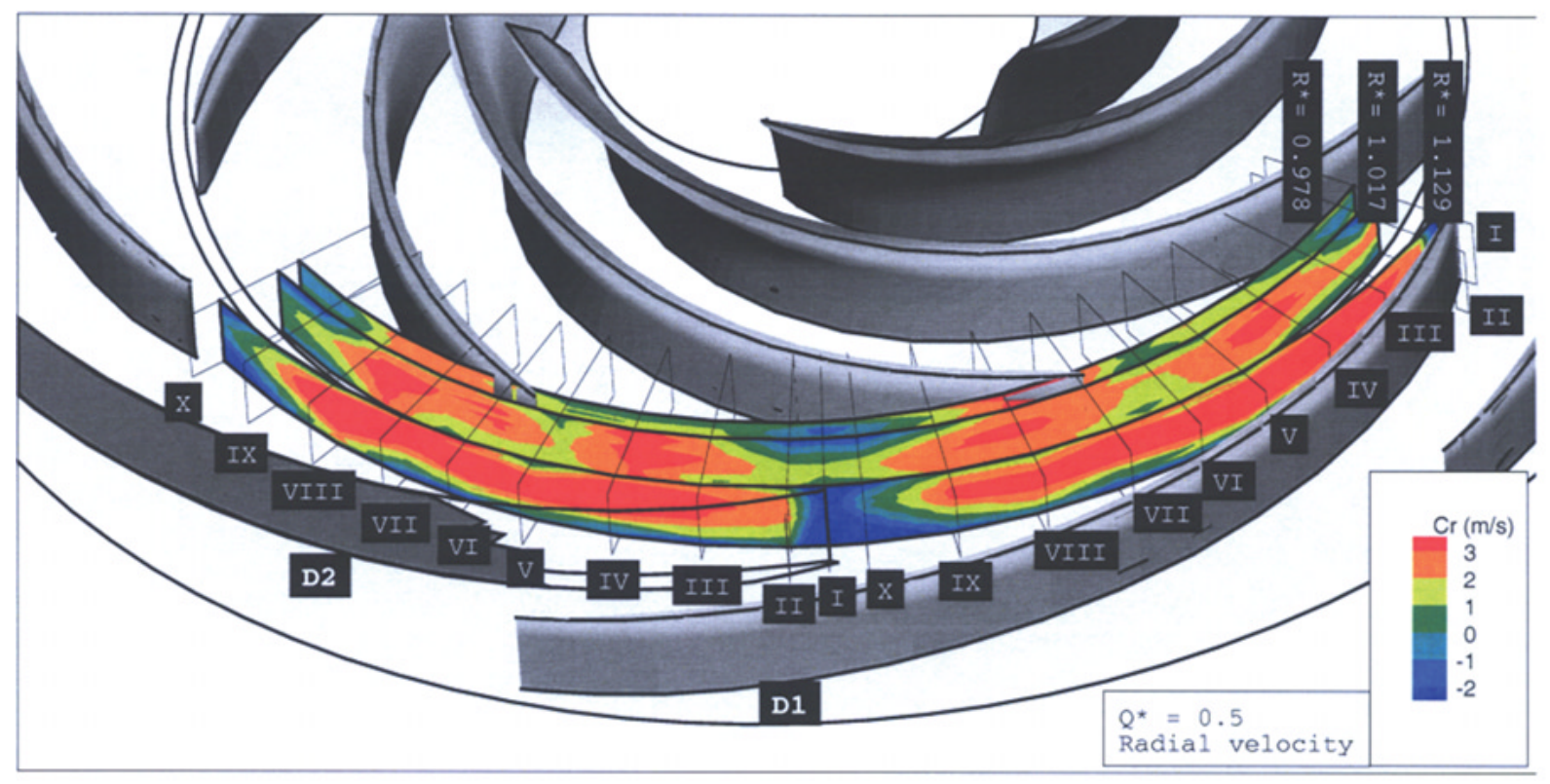

-a-

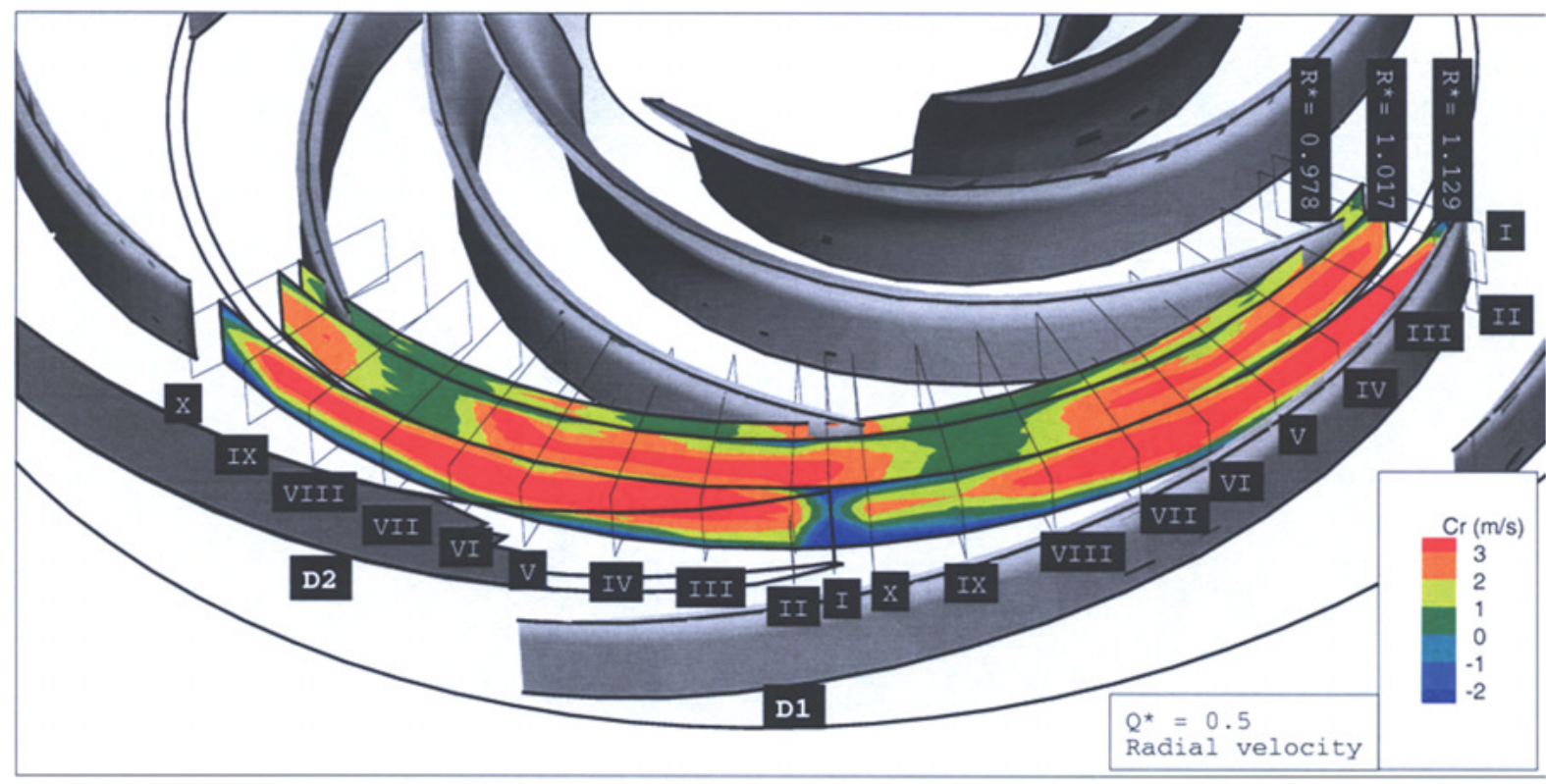

-b-

FIGURE 12

Radial velocity $\mathrm{Cr}$ at $\mathrm{Q}^{*}=0.5$. (a) $\mathrm{T}=12 / 51$; (b) $\mathrm{T}=34 / 51$. 
flow shift towards the passage center. This rotor stator interaction may be explained by a small radial gap $\left(\mathrm{R}_{3} / \mathrm{R}_{2}=1.026\right)$ in the case of the actual machine.

\section{CONCLUSIONS}

An important measuring campaign has been realized on the SHF impeller coupled with a vaned diffuser. The obtained results have permitted a detailed flow reconstitution at the rotor-stator interface. The analysis of the flow structure at different operating conditions revealed a limited influence of the diffuser on the impeller internal flow at the design point.

At $\mathrm{Q}^{*}=0.8$ and at the passage mid-height, the flow distribution in the impeller is independent of the relative position within the diffuser. This operating point seems to be the one at which the impeller and the diffuser are matched and it corresponds to the best efficiency point of the machine. At lower flow rates the diffuser influence is more significant on the impeller and is at the origin of an important flow distortion which can result in extra unsteadiness and strong secondary flows. This rotor-stator interaction may be due to a small radial gap between both pump components and it would be interesting to study the effect of varying the radial gap on the rotor-stator interaction.

\section{REFERENCES}

Akhras, A., El Hajem, M., Morel, R., and Champagne, J. Y. 2000. The internal flow investigation of a centrifugal pump. 10th International Symposium on Applications of Laser Techniques to Fluid Mechanics July 10-13, Lisbon, Portugal.

Akhras, A., El Hajem, M., Morel, R., and Champagne, J. Y. 2001. Internal flow investigation of a centrifugal pump at the design point. Journal of Visualization 4(1):91-98.

Arndt, N., Acosta, A. J., Brennen, C. E., and Caughey, T. K. 1989. Rotorstator interaction in a diffuser pump. Journal of Turbomachinery 111(3):213-221.

Arndt, N., Acosta, A. J., Brennen, C. E., and Caughey, T. K. 1990. Experimental investigation of rotor-stator interaction in a centrifugal pump with several vaned diffusers. Journal of Turbomachinery 112(1):98-108.

Cattani, A., Ottolia, D., Ulbaldi, M., and Zunino, P. 1998. Unsteady boundary layers on the diffuser blades of a centrifugal stage due to rotor blade wake interaction. 9th International Symposium on Applicationas of Laser Techniques to Fluid Mechanics July 13-16, Lisbon, Portugal.

Eckardt, D. 1975. Instantaneous measurements in the jet-wake discharge flow of a centrifugal compressor impeller. Journal of Engineering for Power 337-345.

Eckardt, D. 1976. Detailed flow investigations within a high-speed centrifugal compressor impeller. Journal of Fluids Engineering 390401.

El Hajem, M., Akhras, A., Morel, R., and Champagne. J. Y. 2001. The rotor stator interaction in a centrifugal pump equipped with a vaned diffuser. 4th European Conference On Turbomachinery Fluid Dynamics and Thermodynamics March 20-23, Firenze, Italy.

Inoue, M., and Cumpsty, N. A. 1984. Experimental study of centrifugal impeller discharge flow in vaneless and vaned diffusers. Journal of Engineering for Gas Turbines and Power 106(2):455-467.

Johnston, J. P., and Eide, S. A. 1976. Turbulent boundary layers on centrifugal compressors blades: prediction of the effects of surface curvature and rotation. Journal of Fluids Engineering 374-381.

Johnson, M. W. 1978. Secondary flow in rotating bends. Journal of Engineering for Power 100:553-560.

Krain, H. 1998. Swirling impeller flow. Journal of Turbomachinery 110:122-128.

Liu, C. H., Vafidis, C., and Whitelaw, J. H. 1994. Flow characteristics of a centrifugal pump. Journal of fluids Engineering 116(2):303309.

Miner, S. M., Beaudoin, R. J., and Flack, R. D. 1989. Laser velocimetery measurements in a centrifugal flow pump. Journal of Turbomachinery 111(3):205-212.

Rohne, K. H., and Banzhaf, M. 1991. Investigation of the flow at the exit of unshrouded centrifugal impeller and comparison with the classical jet-wake theory. Journal of Turbomachinery 113:654-659.

Sideris, M. Th., and van den Braembussche, R. A. 1987. Influence of a circumferential exit pressure distortion on the flow in an impeller and diffuser. Journal of Turbomachinery 109(1):48-54.

Ubaldi, M., Zunino, P., and Cattanei, A. 1993. Relative flow and turbulence measurements downstream of a backward centrifugal impeller. Journal of Turbomachinery 115:543-551.

Wuibaut, G., Dupont, P., Bois, G., Caignaert, G., and Stanislas., M. 2001. Analysis of the flow velocities within the impeller and the vaneless diffuser of a radial flow pump, 4th European Conference On Turbomachinery Fluid Dynamics and Thermodynamics. March 20-23, Firenze, Italy. 

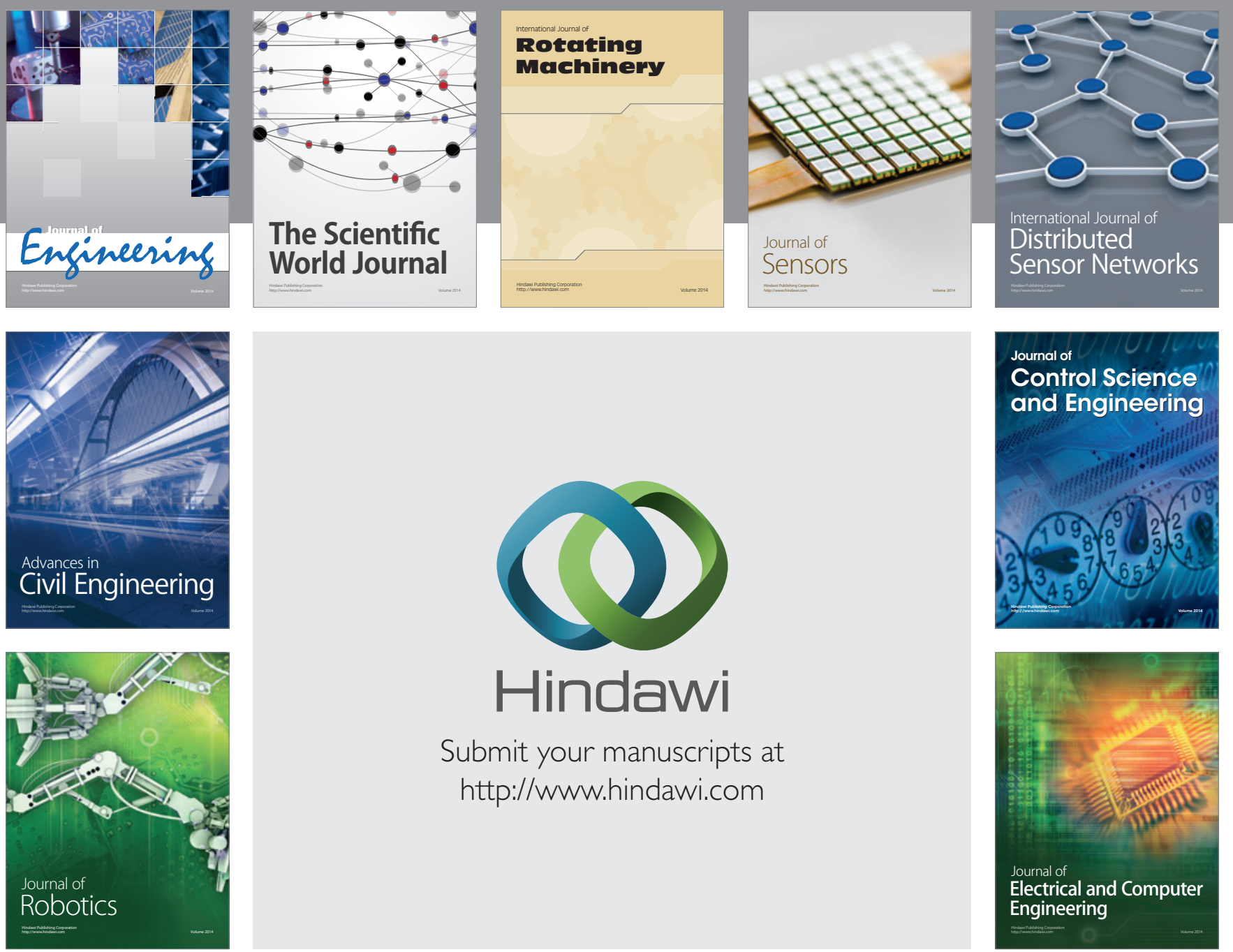

Submit your manuscripts at

http://www.hindawi.com
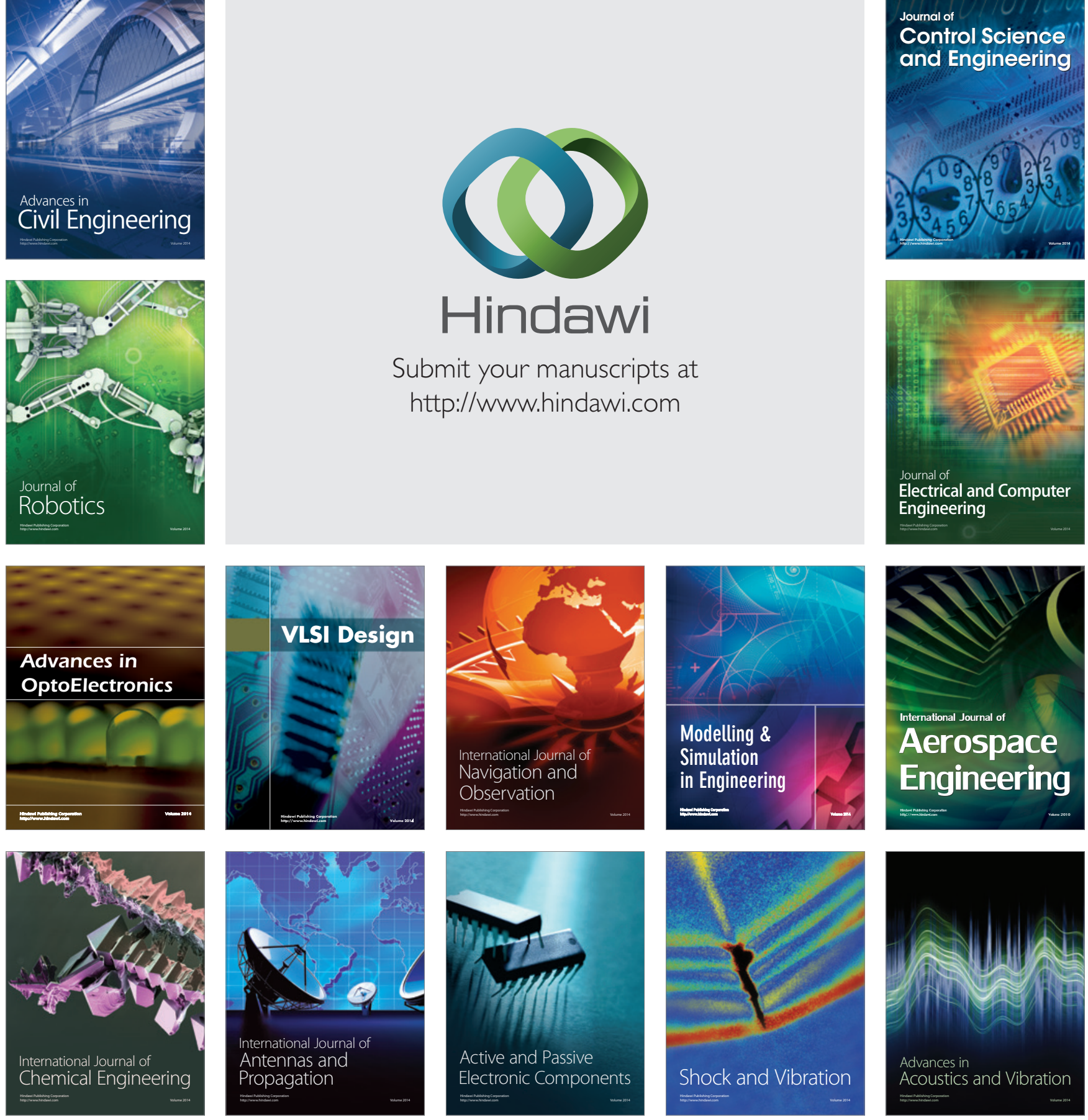